\title{
All-Cause and Potentially Disease-Related Health Care Costs Associated with Venous Thromboembolism in Commercial, Medicare, and Medicaid Beneficiaries
}

\author{
Patrick Lefebvre, MA; François Laliberté, MA; Edith A. Nutescu, PharmD; \\ Mei Sheng Duh, MPH, ScD; Joyce LaMori, MHS, MBA; Brahim K. Bookhart, MBA, MPH; \\ William H. Olson, PhD; Katherine Dea, MA; Jeff Schein, DrPH, MPH; and Scott Kaatz, DO, MSc, FACP
}

\begin{abstract}
BACKGROUND: Patients with venous thromboembolism (VTE) are at increased risk of developing recurrent VTE and post-thrombotic syndrome (PTS), a complication of deep vein thrombosis (DVT) characterized by venous reflux and residual venous obstruction that may manifest as chronic pain and swelling. Therefore, formulary/policy decision makers should understand the clinical and economic consequences associated with VTE.
\end{abstract}

OBJECTIVES: To describe the real-world clinical complications, such as recurrent VTE and PTS, associated with VTE and quantify the incremental direct all-cause and potentially disease-related health care costs associated with VTE.

METHODS: Health insurance claims between January 2004 and December 2008 from the Ingenix Impact database were used. Adult patients with an initial VTE diagnosis (index DVT, pulmonary embolism [PE], or both) with at least 12 months of enrollment prior to the index VTE were matched 1:1 with comparison patients without VTE. Matching criteria included demographic factors, baseline health care costs, and diagnoses of VTE risk factors such as multiple traumas, malignant cancer, or major surgery. Each patient's observation period began on the date of the index VTE, or corresponding study index date for comparison cases, and ended on the earliest of 1 year after the study index date, the health plan disenrollment date, or December 31, 2008. The proportions of patients with (a) recurrent hospitaldocumented VTE, defined as an inpatient episode with a diagnosis of VTE in any claim field; (b) PTS; and (c) other potentially disease-related diagnoses (thrombocytopenia, superficial venous thrombosis, venous ulcer, pulmonary hypertension, stasis dermatitis, and venous insufficiency) were calculated. Health care costs were defined as standardized net provider payments after subtraction of member cost-sharing amounts. All-cause incremental health care costs and disease-related costs, defined as provider payments for hospitalization or outpatient claims with a primary or secondary diagnosis of VTE, PTS, or any of the potentially disease-related diagnoses, were computed. Costs were calculated per patient per year (PPPY) by weighting each patient's total cost for up to 1 year post-index by the length of follow-up.

RESULTS: The matched VTE and no-VTE cohorts included 16,969 subjects in each group. The index VTE event was DVT, PE, or both in 12,711, 2,473, and 1,785 patients, respectively. In the VTE cohort, the risks of recurrent VTE and PTS during the follow-up period (mean [SD] observation of 271.7 [121.6] days) were $3.6 \%$ and $7.1 \%$, respectively. Patients with VTE had significantly higher average PPPY all-cause costs compared with the noVTE patients (mean [SD] \$33,531 [ $\$ 70,393]$ vs. \$17,590 [\$42,011]; cost difference $=\$ 15,941,95 \% \mathrm{Cl}=\$ 14,819-\$ 17,012)$. Corresponding potentially disease-related health care costs PPPY were also significantly higher for the VTE group (mean [SD] $\$ 3,141$ [ $\$ 17,055]$ vs. $\$ 228$ [\$3,221]; cost difference $=\$ 2,913,95 \% \mathrm{Cl}=\$ 2,693-\$ 3,157$ ) and represented $18.3 \%$ (i.e., $\$ 2,913$ of $\$ 15,941$ ) of the all-cause cost difference between the 2 groups.

CONCLUSIONS: In this large matched-cohort study, VTE was associated with a $3.6 \%$ risk of hospital-documented recurrence and a $7.1 \%$ risk of PTS up to
1 year after index VTE. Potentially disease-related costs represented approximately one-fifth of the incremental all-cause costs associated with VTE.

J Manag Care Pharm. 2012;18(5):363-74

Copyright $\odot 2012$, Academy of Managed Care Pharmacy. All rights reserved.

What is already known about this subject

- Venous thromboembolism (VTE; deep vein thrombosis [DVT], pulmonary embolism [PE], or both) occurs in approximately 600,000 hospitalizations each year in the United States and is considered to be the most common preventable cause of hospital death.

- The risk of VTE recurrence among treated patients remains high (6\%-18\% after $1-2$ years). Once VTE occurs, the prognosis is characterized by a 5\%-10\% risk of severe post-thrombotic syndrome (PTS) and other clinical complications, such as chronic thromboembolic pulmonary hypertension, which develops in approximately $5 \%$ of patients after PE.

- The cost burden of VTE is substantial. Previous studies that analyzed large U.S. databases reported that mean total 1-year health care costs associated with VTE were estimated to be $\$ 7,590$ $\$ 33,200$ for DVT, $\$ 13,000-\$ 31,300$ for PE, and up to $\$ 38,300$ for both DVT and PE.

\section{What this study adds}

- This retrospective matched-cohort study used health insurance claims data to quantify the consequences and costs associated with the occurrence of an initial episode of VTE and its subsequent complications. Among patients with VTE, 3.6\% had a hospital-documented VTE recurrence, and $7.1 \%$ had a PTS event during up to 1 year (mean observation of 9 months) following the initial VTE episode (i.e., index VTE event).

- During a follow-up period of up to 1 year after the index VTE event, patients with VTE had significantly higher risks of thrombocytopenia, superficial venous thrombosis, venous ulcer, pulmonary hypertension, stasis dermatitis, and venous insufficiency $(P<0.001$ for all) relative to comparison group patients without VTE.

- During the follow-up period of up to 1 year after the index VTE event, patients with VTE also had significantly higher all-cause health care costs per patient per year compared with no-VTE patients (mean [SD] \$33,531 [\$70,393] vs. $\$ 17,590$ [\$42,011]; cost difference $=\$ 15,941,95 \% \mathrm{CI}=\$ 14,819-\$ 17,012$ ).

- Potentially disease-related health care costs represented nearly one-fifth of the incremental all-cause costs associated with VTE. 
$\mathrm{D}$ eep vein thrombosis (DVT) and pulmonary embolism (PE) constitute venous thromboembolism (VTE), a major health problem with approximately 900,000 incident cases each year in the United States, of which 600,000 occur in the hospital. ${ }^{1}$ Moreover, almost 300,000 deaths each year in the United States have been attributed to $\mathrm{PE}^{1}$ it has been estimated that $2 \%-10 \%$ of all hospital deaths ${ }^{2,3}$ are attributed to PE and that 10\%-25\% of all PE cases result in sudden death. 4.5

The risk of VTE is increased following surgical procedures and trauma and in the presence of cancer or inherited coagulation disorders. ${ }^{6}$ Even with prophylaxis, $1.4 \%-2.9 \%$ of patients develop symptomatic DVT, and PE occurs in $0.4 \%-1.2 \%$ of patients in the 3 months after total knee replacement or total hip replacement. ${ }^{7}$ However, VTE can also develop in patients who are neither hospitalized nor recovering from a major illness. Aging, the use of oral contraceptives, and hormone replacement therapy have all been associated with increased risk of VTE. ${ }^{8,9}$

The risk of VTE recurrence among treated patients remains high, with $5 \%$ of patients experiencing a subsequent DVT or PE within 3 months, $6 \%-18 \%$ within $1-2$ years, and up to $25 \%$ within 5 years of an index event. ${ }^{6,10-12}$ Once VTE occurs, the prognosis is characterized by the risk of post-thrombotic syndrome (PTS) and other complications, such as chronic thromboembolic pulmonary hypertension, which occurs in approximately $5 \%$ of treated patients after PE. ${ }^{5}$ VTE damages deep venous valves and may cause venous reflux and residual venous obstruction, which are largely responsible for the development of PTS. ${ }^{5}$ PTS, which may manifest as chronic pain and swelling, affects $15 \%-50 \% \%^{6,13,14}$ of patients within $1-2$ years of their first DVT, while severe PTS, characterized by debilitating pain, ulceration, and incapacitating limb swelling, affects $5 \%-10 \%$ of DVT patients. ${ }^{6,15}$

Previous studies have reported real-world clinical and economic consequences associated with VTE using statistical methods (e.g., multivariate adjustment and matched design) to reduce the chances of an influential variable (e.g., concomitant disease and baseline resource utilization) confounding the results. ${ }^{16-20}$ However, despite recent trends toward outpatient treatment of VTE and new anticoagulants that are in advanced development for the management of VTE, most of the literature reporting on the consequences and costs associated with VTE is based on data preceding the year 2000. A better and more current understanding of the clinical outcomes and costs of VTE is important for health care systems that strive to reduce their costs and will also aid formulary and policy decision makers in appreciating the cost burden associated with VTE complications.

To fill this gap in the literature, the purposes of the present analysis were (a) to describe the risk of clinical complications (i.e., recurrent VTE and PTS) associated with incident VTE and (b) to quantify the incremental all-cause and potentially disease-related health care costs associated with VTE using recent data from a real-world setting and a matched-cohort design to control for confounding factors that might be associated with VTE.

\section{Methods}

\section{Data Source}

De-identified health insurance claims from the Ingenix National Managed Care Database (Impact) between January 2004 and December 2008 were used to conduct the analysis. This large national database was designed to support benchmarking projects, health care outcomes research, and other research initiatives. The Impact database includes complete medical and pharmacy claims for more than 80 million managed care enrollees in more than 45 health plans throughout the United States. Insurance coverage includes commercial- and government-sponsored (i.e., Medicare and Medicaid) plans. There were more than 30 million members enrolled in 2008, and the average length of enrollment was 25.1 months. Most members were located in the New England (18.1\%), Middle Atlantic (16.6\%), South Atlantic (17.1\%), East North Central (10.5\%), or West South Central (11.9\%) areas of the United States. The distribution by insurance type was as follows: preferred provider organization $(\mathrm{PPO})=31.5 \%$, health maintenance organization $(\mathrm{HMO})=20.7 \%$, point of service $(\mathrm{POS})=40.5 \%$, Medicaid $=1.6 \%$, Medicare $=0.6 \%$, and other $=4.9 \%$.

Data elements used in the present analysis included health plan enrollment records, patient demographics, inpatient and outpatient medical claims, and outpatient pharmacy claims. Any data in the Impact database that might allow identification of individual patients were removed to preserve patient anonymity and comply with the Health Insurance Portability and Accountability Act of 1996.

\section{Study Design}

A retrospective, matched-cohort design was used to compare enrollees with incident VTE with a matched comparison group of no-VTE enrollees. Each patient's observation period began on the date of the first VTE diagnosis (index date) and ended on the earliest of 1 year after the study index date, the health plan disenrollment date, or December 31, 2008. An index date was randomly assigned for each patient in the no-VTE group.

To be included in the study sample, VTE cohort patients were required to meet the following criteria: (a) at least 1 claim with a primary or secondary diagnosis for DVT (International Classification of Diseases, Ninth Revision, Clinical Modification [ICD-9-CM] codes: 451.1x [phlebitis and thrombophlebitis of deep veins of lower extremities], 451.2 [phlebitis and thrombophlebitis of lower extremities unspecified], 453.4x [acute venous embolism and thrombosis of deep vessels of lower extremity], 453.8 [acute venous embolism and thrombosis 
of other specified veins], 453.9 [embolism and thrombosis of unspecified site]) or PE (ICD-9-CM codes 415.1x [pulmonary embolism and infarction]); (b) continuous health plan enrollment in the 12 months prior to the index date (baseline period); and (c) at least 18 years of age on the index date (i.e., first VTE event).

Of note, we identified patients with incident VTE in the current study. We did not include codes for chronic venous embolism and thrombosis of deep vessels of lower extremity (ICD-9-CM code: 453.5x) or chronic venous embolism and thrombosis of deep veins of upper extremity (ICD-9-CM code: 453.72) in our definition of incident VTE because of the chronic nature of these diagnoses.

We imposed a minimum of 12 months of insurance coverage prior to the index date to assess the baseline characteristics of the study population in order to appropriately control for confounding factors in matching VTE cases with no-VTE comparison cases. No further minimum follow-up time was imposed during the observation period to avoid introducing potential bias such as survival or observation bias.

\section{Outcome Measures}

Primary Endpoints. The primary endpoints of the study, which were evaluated only for the VTE group, included (a) the risk of recurrent VTE documented during an inpatient stay and (b) PTS. Hospitalization data were obtained from the Impact Inpatient Confinement table, which provided a summarized record for each inpatient episode with a length of stay of at least 1 day in an acute care hospitalization or skilled nursing facility setting. Recurrent VTE events were defined as inpatient episodes with a diagnosis for acute VTE in the admitting or any other diagnosis fields occurring at any time following the index VTE event (either as a VTE event requiring hospitalization or VTE secondary to a primary diagnosis). Based on the algorithm developed by MacDougall et al. (2006), ${ }^{16}$ PTS was defined as the occurrence 90 or more days after an index VTE of both a venous imaging procedure (Current Procedural Terminology [CPT]-4 codes 93965, 93970, or 93971) and 1 or more of the following, based on diagnosis codes (see Appendix): both pain and swelling of the limb within 7 days of each other, varicose veins of the lower extremities, postphlebitic syndrome, and other disorders of the circulatory system.

Exploratory Endpoints. Additional exploratory endpoints were identified a priori based on the literature reviewed by the authors during the study protocol development prior to conducting the study analyses. ${ }^{21-31}$ These exploratory endpoints included thrombocytopenia, superficial venous thrombosis, venous ulcer, pulmonary hypertension, stasis dermatitis, and venous insufficiency (Appendix).

Most of these endpoints have been identified in the literature as VTE-related complications, although some co-occur with or after VTE and may not be caused by VTE. Heparininduced thrombocytopenia can complicate heparin therapy for VTE, ${ }^{21}$ and thrombocytopenia not related to heparin usage may also be developed by patients with VTE. ${ }^{22}$ Superficial venous thrombosis has been described as a venous condition interrelated with $\mathrm{VTE},{ }^{23}$ and at the beginning of a large prospective study of patients with superficial venous thrombosis, about one-quarter also had DVT. ${ }^{24}$ Venous ulcer and pulmonary hypertension have been reported as major complications of VTE. ${ }^{25}$ DVT is noted as the most consistently observed risk factor for venous ulcer because it directly destroys and indirectly impairs venous valves. ${ }^{26}$ A prospective study conducted by Pengo et al. (2004) found that chronic thromboembolic pulmonary hypertension affects approximately $4 \%$ of patients within 2 years after a first episode of $\mathrm{PE}$ and is a serious complication of PE. ${ }^{27}$ A review by Vedantham (2009) reported that stasis dermatitis may occur in severe cases of PTS. ${ }^{28}$ Stasis dermatitis can also develop following chronic venous insufficiency. ${ }^{29}$

DVT can affect the structural integrity of vein valves, which, if in poor condition, may fail to appropriately coapt and prevent retrograde flow. Loss of the efficiency of the venous outflow system and reflux of venous blood down the leg lead to symptoms of chronic venous insufficiency. ${ }^{26} \mathrm{~A}$ study by Yamaki and Nozaki (2005) investigated patterns of venous insufficiency after DVT and found that the limbs involving multisegment DVTs on initial examination had a higher incidence of deep vein insufficiency compared with single segment DVT. ${ }^{30}$ A study by Juhan et al. (1997) also reported that among patients with surgical venous thrombectomy, the surgical removal of a large blood clot, the rate of valvular insufficiency was $20 \%$ at 5 years and $44 \%$ at 10 years. ${ }^{31}$

These potentially disease-related, exploratory endpoints were studied separately from PTS as independent outcomes. However, some ICD-9-CM codes used to define the exploratory endpoints overlap with the definition of PTS (Appendix). For example, venous ulcer was an exploratory endpoint, but the ICD-9-CM codes 459.11 (postphlebitic syndrome with ulcer) and 459.13 (postphlebitic syndrome with ulcer and inflammation) are also part of the ICD-9-CM code 459.1 (postphlebitic syndrome) used to define PTS. Also, for the exploratory endpoints, a venous imaging procedure was not required.

Incremental health care costs associated with VTE were also calculated and categorized as (a) total health care costs, defined as all-cause outpatient, hospitalization, and pharmacy costs, and (b) potentially disease-related costs, defined as hospitalizations and outpatient claims with a primary or secondary diagnosis for VTE, PTS, or any of the exploratory endpoints. Results were also stratified by gender and baseline risk factors for VTE.

Cost Outcomes. Impact has developed several approaches (e.g., proprietary algorithms and multivariate models) for 
TABLE 1 Characteristics of the Overall VTE and No-VTE Cohorts (Before Random Sampling and Matching)

\begin{tabular}{|c|c|c|c|c|c|c|c|c|c|}
\hline \multirow{3}{*}{$\begin{array}{l}\text { Characteristics } \\
\text { Observation period, }{ }^{\mathrm{a}} \\
\text { mean [SD] days }\end{array}$} & \multicolumn{2}{|c|}{$\begin{array}{l}\text { VTE Group } \\
\mathrm{n}=177,885\end{array}$} & \multicolumn{2}{|c|}{$\begin{array}{l}\text { No-VTE Group } \\
\mathrm{n}=253,521\end{array}$} & \multirow{2}{*}{$\frac{\text { Characteristics }}{\text { Most frequent VTE risk fact }}$} & \multicolumn{2}{|c|}{$\begin{array}{l}\text { VTE Group } \\
\mathrm{n}=177,885\end{array}$} & \multicolumn{2}{|c|}{$\begin{array}{l}\text { No-VTE Group } \\
\mathbf{n}=253,521\end{array}$} \\
\hline & \multirow[t]{2}{*}{271.8} & \multirow[t]{2}{*}[121.0]{} & \multirow[t]{2}{*}{268.1} & \multirow[t]{2}{*}[108.8]{} & & $\%(n)$ & & & \\
\hline & & & & & Multiple trauma & 31.3 & $(55,619)$ & 17.9 & $(45,263)$ \\
\hline \multicolumn{5}{|l|}{ Type of index VTE, \% (n) } & Other serious infections & 22.6 & $(40,184)$ & 13.9 & $(35,297)$ \\
\hline DVT only & 74.4 & $(132,360)$ & & & Malignant cancer & 18.0 & $(31,956)$ & 8.7 & $(21,943)$ \\
\hline PE only & 14.7 & $(26,098)$ & & & Abdominal surgery & 17.0 & $(30,227)$ & 9.3 & $(23,610)$ \\
\hline $\mathrm{PE}$ and DVT & 10.9 & $(19,427)$ & & & Major surgery & 14.5 & $(25,859)$ & 3.5 & $(8,876)$ \\
\hline \multicolumn{5}{|c|}{ Propensity score matching factors ${ }^{b, c}$} & COPD & 13.5 & $(24,081)$ & 6.4 & $(16,134)$ \\
\hline \multicolumn{5}{|c|}{ Exact matching factors ${ }^{b}$} & Use of anticoagulant, \% (n) & 11.7 & $(20,732)$ & 2.3 & $(5,738)$ \\
\hline \multicolumn{5}{|c|}{ History of exploratory endpoint outcomes, \% (n) } & \multicolumn{5}{|l|}{ Region, \% (n) } \\
\hline Venous insufficiency & 4.9 & $(8,798)$ & 0.7 & $(1,873)$ & Middle Atlantic & 22.4 & $(39,861)$ & 39.0 & $(98,813)$ \\
\hline Stasis dermatitis & 2.0 & $(3,511)$ & 0.3 & $(688)$ & New England & 21.5 & $(38,252)$ & 51.9 & $(131,564)$ \\
\hline $\begin{array}{l}\text { Superficial venous } \\
\text { thrombosis }\end{array}$ & 1.7 & $(2,971)$ & 0.1 & (218) & South Atlantic & 18.4 & $(32,734)$ & 2.5 & $(6,218)$ \\
\hline $\begin{array}{l}\text { thrombosis } \\
\text { Thrombocytopenia }\end{array}$ & 20 & $(3572)$ & 04 & (1) & East North Central & 10.8 & $(19,238)$ & 0.7 & $(1,699)$ \\
\hline Pulmonary hypertension & $\frac{2.0}{1.5}$ & $\frac{(3,3 / 2)}{(2,737)}$ & 0.3 & $\frac{(1,0<2)}{(763)}$ & West South Central & 9.3 & $(16,563)$ & 0.4 & $(905)$ \\
\hline Venous ulcer & 1.1 & $(2,044)$ & 0.1 & $(373)$ & Mountain & 7.3 & $(12,935)$ & 4.2 & $(10,579)$ \\
\hline \multicolumn{5}{|c|}{ Other propensity score matching factors ${ }^{b}$} & West North Central & 4.7 & $(8,414)$ & 0.4 & (969) \\
\hline \multicolumn{5}{|c|}{ All-cause health care costs at baseline, mean [SD] \$ } & Pacific & 2.9 & $(5,157)$ & 0.7 & $(1,879)$ \\
\hline Outpatient services & 9,990 & {$[17,618]$} & 3,488 & {$[7,298]$} & East South Central & 2.6 & $(4,641)$ & 0.3 & $(771)$ \\
\hline Inpatient services & 11,259 & {$[24,076]$} & 1,575 & {$[8,185]$} & Other & 0.1 & $(90)$ & 0.0 & $(124)$ \\
\hline Pharmacy costs & 2,355 & {$[4,579]$} & 1,314 & {$[2,770]$} & \multicolumn{5}{|l|}{ Type of insurance, \% (n) } \\
\hline Age in years, mean [SD] & 54.6 & [14.2] & 54.4 & {$[13.8]$} & $\mathrm{PPO}$ & 28.9 & $(51,471)$ & 38.4 & $(97,227)$ \\
\hline Female, \% (n) & 57.4 & $(102,031)$ & 56.9 & $(144,229)$ & $\mathrm{HMO}$ & 29.1 & $(51,749)$ & 47.0 & $(119,115)$ \\
\hline \multicolumn{5}{|c|}{ Charlson comorbidity index, \% (n) } & POS & 37.5 & $(66,666)$ & 8.7 & $(22,015)$ \\
\hline 0 & 43.2 & $(76,879)$ & 70.4 & $(178,579)$ & Other & 4.5 & $(7,999)$ & 6.0 & $(15,164)$ \\
\hline 1 & 20.4 & $(36,302)$ & 15.8 & $(40,053)$ & \multicolumn{5}{|l|}{ Index year, \% (n) } \\
\hline 2 & 13.3 & $(23,728)$ & 7.9 & $(20,059)$ & 2005 & 27.8 & $(49,406)$ & 31.0 & $(78,526)$ \\
\hline 3 & 7.4 & $(13,186)$ & 2.8 & $(7,158)$ & 2006 & 24.1 & $(42,927)$ & 23.2 & $(58,827)$ \\
\hline 4 & 4.1 & $(7,317)$ & 1.2 & $(2,968)$ & 2007 & 25.4 & $(45,235)$ & 24.4 & $(61,974)$ \\
\hline 5 or more & 11.5 & $(20,473)$ & 1.9 & $(4,704)$ & 2008 & 22.7 & $(40,317)$ & 21.4 & $(54,194)$ \\
\hline
\end{tabular}

aThe observation period spanned from the index date until the earliest of the following: health plan disenrollment, 12 months after the index date, or the end of the study period on December 31, 2008.

${ }^{b}$ Evaluated during the 1-year baseline period.

'Table shows only factors observed in at least 10\% of the sample. Additional propensity score matching factors not reported in this table include the following VTE risk factors observed in less than $10 \%$ of the study sample: use of oral contraceptive pill; obesity; pneumonia; pregnancy; hip, pelvis, or leg fracture; congestive heart failure; varicose veins; ischemic stroke; treatment with selective estrogen receptor modulators; rheumatoid arthritis; transient ischemic attack; central venous catheter; thrombophilia; inflammatory bowel disease; surgical resection of abdominal pelvic cancer; treatment with erythropoiesis-stimulating agents; myocardial infarction; spinal cord injury; treatment with aromatase inhibitors; immobility; estrogen replacement therapy; and hip or knee surgery.

$C O P D=$ chronic obstructive pulmonary disease; $D V T=$ deep vein thrombosis; HMO = health maintenance organization; $P E=$ pulmonary embolism; POS = point of service; $P P O=$ preferred provider organization; $S D=$ standard deviation; $V T E=$ venous thromboembolism.

standardizing pricing for different service categories (inpatient facility, outpatient facility, professional services, ancillary services, and pharmacy claims) across health plans in order to develop a database that accounts for differences in provider contracting and other pricing variations. The costs are reported from the payer's perspective. Deductibles, copayment, coinsurance, and other cost-sharing amounts have been subtracted from the total allowed charge so that consistent comparisons may be made across all patients, health plans, and geographic areas. The resulting cost figures are therefore comparable across health plans and reflect net provider payments after sub- traction of member cost sharing. Costs were inflation adjusted to reflect 2008 U.S. dollar market value.

\section{Random Sampling}

Since the primary purpose of the study was to assess the clinical and economic impact of VTE in patients who experienced a VTE event, our initial intention was to include all VTE cases in the matched cohort. Ideally the no-VTE group would have been very large relative to the VTE group in order to find a no-VTE comparison for each VTE case, especially given the important imbalance in baseline characteristic profiles of these 2 groups (Table 1). However, due to the limited number of 


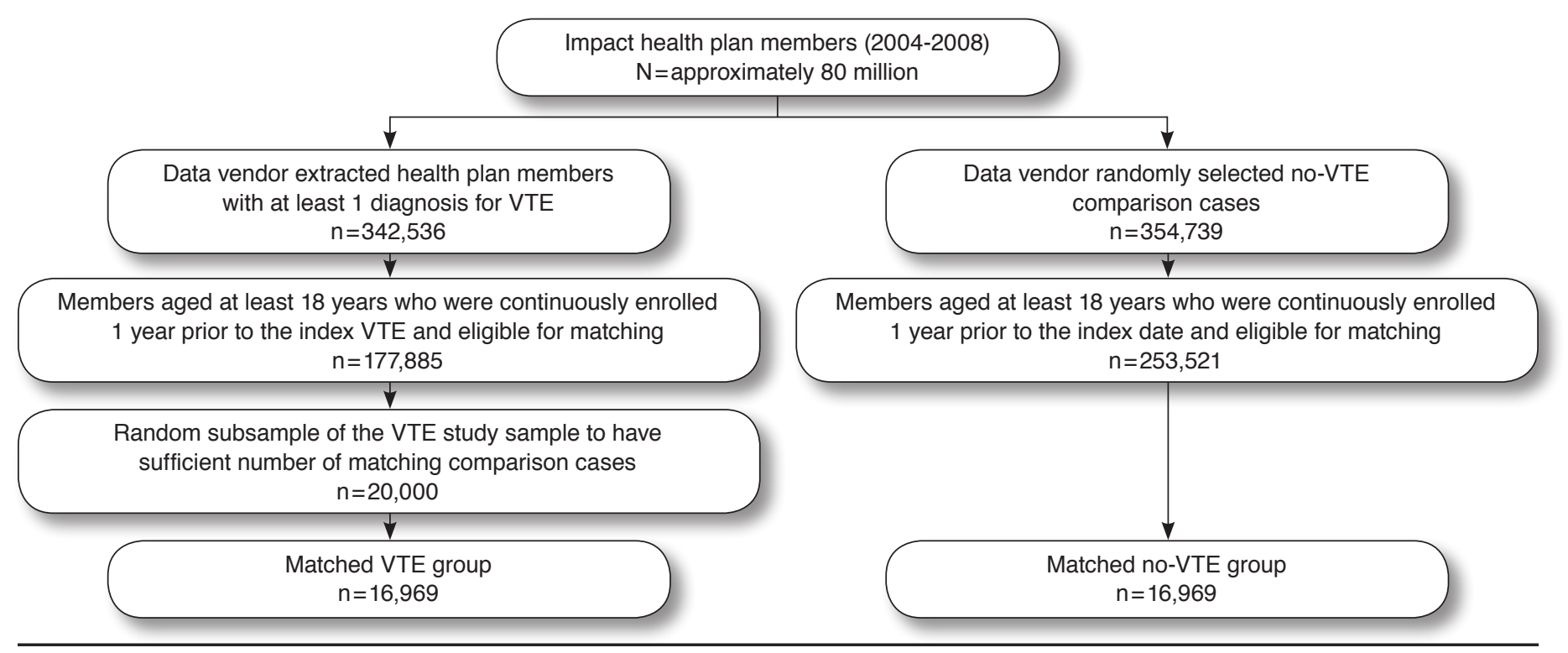

VTE = venous thromboembolism.

potential comparison group cases that we received from the data vendor during the data extraction, the no-VTE comparison group eligible for matching $(\mathrm{n}=253,521)$ was similar in size to the VTE group $(n=177,885)$. A random sample of 20,000 VTE patients obtained with a random number generator was thus selected. Random samples of 40,000,30,000, and 25,000 VTE patients were also tried but did not allow the matching of enough (i.e., more than $80 \%$ of the VTE cohort) VTE patients to stay representative of the overall VTE cohort.

\section{Matching Algorithm}

Given the large sample of VTE patients available for the analysis and because the power to detect differences between cohorts was not an issue for the current study even after random sampling, a matched-cohort design was chosen over a regression analysis. As observed by Rosenbaum and Rubin (1985), one of the advantages of matching over regression analyses is that simple descriptive statistics can be used to summarize the findings and compare the matched cohorts. ${ }^{32}$

To attempt to create cohorts with balanced patient characteristics at baseline, VTE patients were matched 1:1 to noVTE patients based on exact matching factors and propensity scores. The predictors used in the propensity score calculation included baseline (12 months pre-index) diagnoses of thrombocytopenia, superficial venous thrombosis, venous ulcer, pulmonary hypertension, stasis dermatitis, and venous insufficiency (i.e., the potentially disease-related diagnoses); all-cause health care costs; demographic characteristics (age, gender, region, and type of insurance); Charlson comorbidity index; and risk factors for VTE (Tables 1 and 2) identified in the literature review.

The dependent variable in the propensity score model was a binary indicator of an index VTE (yes/no), estimating the propensity for VTE based on observable baseline characteristics. The c-statistic for the logistic regression analysis used to develop the propensity score algorithm was 0.875 , which indicates excellent discrimination. ${ }^{33}$

Following propensity score calculations, VTE patients were matched (a) exactly to no-VTE patients based on the potentially disease-related, exploratory endpoints (thrombocytopenia, superficial venous thrombosis, venous ulcer, pulmonary hypertension, stasis dermatitis, and venous insufficiency during the 12-month baseline period) and (b) by propensity score intervals of $25 \%$. Smaller propensity score intervals were also tested but proved to be too restrictive due to the very different baseline characteristic profiles of the VTE and no-VTE groups. For the exact matching on exploratory endpoints, patients were matched on specific diagnoses (e.g., a VTE patient with thrombocytopenia and venous ulcer was matched to a no-VTE patient with thrombocytopenia and venous ulcer).

\section{Statistical Analyses}

The risks of each outcome measure (recurrent VTE documented during a hospital stay, PTS, and exploratory endpoints) for VTE patients were evaluated using absolute risk rates throughout the observation period as well as incidence rates 
All-Cause and Potentially Disease-Related Health Care Costs Associated with

Venous Thromboembolism in Commercial, Medicare, and Medicaid Beneficiaries

TABLE 2 Characteristics of the Study Sample After Matching VTE and No-VTE Comparison Patients

\begin{tabular}{|c|c|c|c|c|c|c|c|c|c|c|c|}
\hline \multirow{3}{*}{$\begin{array}{l}\text { Characteristics } \\
\text { Observation period, }{ }^{a} \\
\text { mean [SD] days }\end{array}$} & \multicolumn{2}{|c|}{$\begin{array}{l}\text { VTE Group } \\
\mathbf{n}=16,969\end{array}$} & \multicolumn{2}{|c|}{$\begin{array}{l}\text { No-VTE Group } \\
n=16,969\end{array}$} & \multirow{3}{*}{$\mid \begin{array}{l}P \text { Value } \\
<0.001\end{array}$} & Characteristics & \multicolumn{2}{|c|}{$\begin{array}{l}\text { VTE Group } \\
\mathrm{n}=16,969\end{array}$} & \multicolumn{2}{|c|}{$\begin{array}{l}\text { No-VTE Group } \\
\quad \mathrm{n}=16,969\end{array}$} & \multirow[t]{2}{*}{$P$ Value } \\
\hline & 271.7 & [121.6] & 257.9 & {$[112.3]$} & & \multicolumn{5}{|c|}{ Most frequent VTE risk factors, ${ }^{\mathrm{c}} \%$ (n) } & \\
\hline & & & & & & Multiple trauma & 30.9 & $(5,249)$ & 31.4 & $(5,333)$ & 0.322 \\
\hline \multicolumn{6}{|l|}{ Type of index VTE, \% (n) } & Other serious infections & 22.1 & $(3,748)$ & 23.1 & $(3,916)$ & 0.029 \\
\hline DVT only & 74.9 & $(12,711)$ & & & & Malignant cancer & 17.4 & $(2,952)$ & 17.7 & $(3,006)$ & 0.442 \\
\hline PE only & 14.6 & $(2,473)$ & & & & Abdominal surgery & 17.0 & $(2,893)$ & 16.7 & $(2,827)$ & 0.340 \\
\hline PE and DVT & 10.5 & $(1,785)$ & & & & Major surgery & 13.7 & $(2,319)$ & 12.3 & $(2,090)$ & 0.001 \\
\hline \multicolumn{6}{|c|}{ Propensity score matching factors $\mathrm{b}, \mathrm{c}$} & COPD & 13.1 & $(2,222)$ & 13.7 & $(2,332)$ & 0.079 \\
\hline \multicolumn{6}{|c|}{ Exact matching factors ${ }^{b}$} & Use of anticoagulant, & 10.9 & $(1,855)$ & 11.8 & $(1,995)$ & 0.015 \\
\hline \multicolumn{6}{|c|}{ History of exploratory endpoint outcomes, \% (n) } & $\%(\mathbf{n})$ & & & & & \\
\hline Venous insufficiency & 5.4 & (910) & 5.4 & $(910)$ & 1.000 & \multicolumn{6}{|l|}{ Region, \% (n) } \\
\hline Stasis dermatitis & 2.1 & (349) & 2.1 & $(349)$ & 1.000 & Middle Atlantic & 25.2 & $(4,272)$ & 29.0 & $(4,919)$ & \\
\hline \multirow{2}{*}{$\begin{array}{l}\text { Superficial venous } \\
\text { thrombosis }\end{array}$} & \multirow[t]{2}{*}{1.1} & \multirow[t]{2}{*}{ (195) } & \multirow[t]{2}{*}{1.1} & \multirow[t]{2}{*}{ (195) } & \multirow[t]{2}{*}{1.000} & New England & 24.4 & $(4,146)$ & 34.1 & $(5,784)$ & \\
\hline & & & & & & South Atlantic & 16.7 & $(2,834)$ & 13.5 & $(2,290)$ & \\
\hline Thrombocytopenia & 1.9 & $(328)$ & 1.9 & $(328)$ & 1.000 & East North Central & 9.2 & $(1,554)$ & 5.8 & $(985)$ & \\
\hline Pulmonary hypertension & 1.6 & $(275)$ & 1.6 & $(275)$ & 1.000 & West South Central & 8.0 & $(1,354)$ & 5.3 & $(899)$ & $<0.001$ \\
\hline Venous ulcer & 1.1 & (191) & 1.1 & $(191)$ & 1.000 & Mountain & 7.3 & $(1,241)$ & 5.4 & (919) & \\
\hline \multicolumn{6}{|c|}{ Other propensity score matching factors ${ }^{b}$} & West North Central & 4.2 & $(711)$ & 2.7 & $(463)$ & \\
\hline \multicolumn{6}{|c|}{ All-cause health care costs at baseline, mean [SD] \$ } & Pacific & 2.6 & $(448)$ & 2.6 & $(439)$ & \\
\hline Outpatient services & 9,496 & {$[16,948]$} & 9,823 & {$[19,276]$} & 0.083 & East South Central & 2.4 & $(401)$ & 1.5 & (263) & \\
\hline Inpatient services & 10,471 & {$[23,158]$} & 10,812 & {$[24,394]$} & 0.160 & Other & 0.0 & (8) & 0.0 & (8) & \\
\hline Pharmacy costs & 2,251 & {$[4,294]$} & 2,333 & {$[5,325]$} & 0.115 & \multicolumn{6}{|l|}{ Type of insurance, \% (n) } \\
\hline Age in years, mean [SD] & 54.6 & [14.2] & 56.5 & [14.6] & $<0.001$ & $\mathrm{PPO}$ & 30.8 & $(5,232)$ & 41.9 & $(7,116)$ & \\
\hline Female, \% (n) & 56.9 & $(9,654)$ & 57.0 & $(9,667)$ & 0.895 & $\mathrm{HMO}$ & 30.8 & $(5,221)$ & 36.4 & $(6,170)$ & $<0.001$ \\
\hline \multicolumn{6}{|c|}{ Charlson comorbidity index, \% (n) } & POS & 33.8 & $(5,738)$ & 15.0 & $(2,551)$ & \\
\hline 0 & 44.6 & $(7,567)$ & 49.4 & $(8,381)$ & $<0.001$ & Other & 4.6 & $(778)$ & 6.7 & $(1,132)$ & \\
\hline 1 & 20.2 & $(3,425)$ & 15.9 & $(2,692)$ & & \multicolumn{6}{|l|}{ Index year, \% (n) } \\
\hline 2 & 13.5 & $(2,288)$ & 10.8 & $(1,832)$ & & 2005 & 28.4 & $(4,823)$ & 31.3 & $(5,316)$ & \\
\hline 3 & 7.2 & $(1,223)$ & 6.4 & $(1,094)$ & & 2006 & 23.8 & $(4,036)$ & 23.1 & $(3,914)$ & $<0.001$ \\
\hline 4 & 3.7 & $(630)$ & 4.2 & $(716)$ & & 2007 & 25.5 & $(4,331)$ & 24.3 & $(4,129)$ & \\
\hline 5 or more & 10.8 & $(1,836)$ & 13.3 & $(2,254)$ & & 2008 & 22.3 & $(3,779)$ & 21.3 & $(3,610)$ & \\
\hline
\end{tabular}

aThe observation period spanned from the index date until the earliest of the following: health plan disenrollment, 12 months after the index date, or the end of the study period on December 31, 2008.

${ }^{b}$ Evaluated during the 1-year baseline period.

'Table shows only factors observed in at least 10\% of the sample. Additional propensity-score matching factors not reported in this table include the following VTE risk factors observed in less than 10\% of the study sample: use of oral contraceptive pill; obesity; pneumonia; pregnancy; hip, pelvis, or leg fracture; congestive heart failure; varicose veins; ischemic stroke; treatment with selective estrogen receptor modulators; rheumatoid arthritis; transient ischemic attack; central venous catheter; thrombophilia; inflammatory bowel disease; surgical resection of abdominal pelvic cancer; treatment with erythropoiesis-stimulating agents; myocardial infarction; spinal cord injury; treatment with aromatase inhibitors; immobility; estrogen replacement therapy; and hip or knee surgery.

$C O P D=$ chronic obstructive pulmonary disease; $D V T=$ deep vein thrombosis; HMO = health maintenance organization; $P E=$ pulmonary embolism; $P O S=$ point of service; $P P O=$ preferred provider organization; $S D=$ standard deviation; VTE = venous thromboembolism.

per 100 patient-years to account for variable length of followup. The absolute risk of an event was calculated as the number of patients with the event divided by the total number of patients. Incidence rate was calculated as the number of events divided by the patient-years of observation, censored at the time of the first event. In addition, the risks of the exploratory endpoint measures were compared between VTE and no-VTE cohorts using risk ratios (RRs) and incidence rate ratios (IRRs). The RR was calculated as the absolute risk in the VTE group divided by that in the no-VTE group, whereas the IRR was calculated as the incidence rate of the VTE group divided by that of the no-VTE group. Ninety-five percent confidence intervals (CIs) of RRs and IRRS were calculated based on the binomial and Poisson probability distributions, respectively.

Cost differences between study cohorts were assessed based on incremental annualized costs. To avoid overestimating costs by annualizing data for patients observed for less than 1 year, we calculated costs per patient per year (PPPY) by weighting each patient's cost outcomes by length of follow-up. ${ }^{34,35}$ Because the normality assumption might not be valid for cost-outcome variables, we conducted nonparametric estimations (i.e., bootstrap method) to carry out statistical inference and determine 
the $95 \%$ CI for the cost difference between the 2 groups. This method estimates the empirical distributional function of the data without imposing any probability density function. ${ }^{36,37}$

Descriptive statistics were used to describe the baseline characteristics of the matched VTE and no-VTE cohorts, including mean (standard deviation [SD]) for continuous data and relative frequencies for categorical data. Baseline continuous variables were compared using paired t tests, while baseline categorical variables were compared using Pearson chi-squared or McNemar tests. A 2-sided alpha level of 0.05 was used to define statistical significance. All statistical analyses were performed using SAS version 9.1 (SAS Institute, Inc., Cary, NC).

\section{Results}

\section{Characteristics of the Matched Cohorts}

Figure 1 summarizes the study sample selection. Among the random subsample of 20,000 VTE patients, 16,969 (84.8\%) were matched, and these randomly selected VTE patients had baseline characteristics that were similar to those of the whole VTE sample (Tables 1 and 2). Overall, the VTE and no-VTE cohorts were well matched with respect to demographic characteristics, baseline exploratory endpoints, risk factors, and baseline health care costs (Table 2).

The index VTE event was DVT, PE, or both in 12,711 (74.9\%), 2,473 (14.6\%), and 1,785 (10.5\%) patients, respectively. The most frequent baseline risk factors for VTE, occurring in more than $10 \%$ of patients, were multiple trauma, other serious infection, malignant cancer, abdominal surgery, major surgery, and chronic obstructive pulmonary disease (COPD). The mean (SD; range) observation periods for the VTE and no-VTE cohorts were 272 (122; 1-365) and 258 (112; 32-365) days, respectively.

\section{Risk of Complications and Exploratory Endpoints}

Table $3 a$ presents the absolute risk, incidence rate, and mean time to first event for recurrent VTE and PTS up to 1 year and up to 6 months after the index date for the overall VTE sample and matched VTE cohort. Of note, the risks and incidence rates of recurrent VTE and PTS were similar between the overall VTE sample and the matched VTE cohort. Absolute risks of recurrent VTE and PTS up to 1 year after the index date for the matched VTE cohort were $3.6 \%$ and $7.1 \%$, respectively. The corresponding risks up to 6 months after the index date were $3.1 \%$ and $4.2 \%$, respectively (Table 3a). Similar trends were observed for the incidence rate results. Risks and incidence rates of the potentially disease-related, exploratory endpoints were all significantly higher for the VTE group compared with the no-VTE group $(P<0.001$ for all comparisons, Table $3 b)$.

For the stratified analysis by gender and baseline VTE risk factors (Table 4), the absolute risks of recurrent VTE measured throughout the observation period were $4.3 \%$ for male and
TABLE 3a

Risk and Incidence Rates of Recurrent VTE and Post-Thrombotic Syndrome for the VTE Cohort

\begin{tabular}{|c|c|c|c|c|}
\hline Primary Endpoints & $\begin{array}{c}\text { Risk } \\
\text { of } \\
\text { Event } \\
(\%)\end{array}$ & $\begin{array}{c}\text { IR Per } \\
100 \\
\text { Patient- } \\
\text { Years }\end{array}$ & $\begin{array}{c}\text { Mean [SD] } \\
\text { Days to } \\
\text { Event }^{\mathrm{a}}\end{array}$ & $\begin{array}{c}\text { Mean } \\
\text { (Median) } \\
\text { Follow-Up } \\
\text { Time in } \\
\text { Days }\end{array}$ \\
\hline
\end{tabular}

Up to 1 Year of Follow-Up

Recurrent VTE documented during inpatient stay

\begin{tabular}{|c|c|c|c|c|}
\hline Overall VTE sample $(n=177,885)$ & 3.9 & 5.4 & $70.8[87.7]$ & $271.8(365)$ \\
\hline Matched VTE cohort $(n=16,969)$ & 3.6 & 5.0 & $75.3[91.5]$ & $271.7(365)$ \\
\hline \multicolumn{5}{|l|}{ Stratified by type of index VTE } \\
\hline $\operatorname{DVT}(\mathrm{n}=12,711)$ & 2.2 & 3.0 & 79.7 [94.0] & 274.5 \\
\hline $\mathrm{PE}(\mathrm{n}=2,473)$ & 1.6 & 2.3 & $43.1[66.3]$ & $256.0(336)$ \\
\hline Both $(n=1,785)$ & 16.1 & 24.3 & $75.4[91.4]$ & $273.6(365)$ \\
\hline \multicolumn{5}{|l|}{ Post-thrombotic syndrome ${ }^{b}$} \\
\hline Overall VTE sample $(n=153,607)$ & 6.9 & 8.5 & $175.6[73.7]$ & $307.1(365)$ \\
\hline Matched VTE cohort $(n=14,647)$ & 7.1 & 8.8 & $176.7[73.3]$ & $307.2(365)$ \\
\hline \multicolumn{5}{|l|}{ Stratified by type of index VTE } \\
\hline DVT $(\mathrm{n}=11,067)$ & 6.5 & 9.6 & $174.1[73.2]$ & $308.0(365)$ \\
\hline $\mathrm{PE}(\mathrm{n}=2,033)$ & 1.9 & 2.7 & $197.1[77.8]$ & $302.2(365)$ \\
\hline Both $(n=1,547)$ & 9.4 & 13.3 & $183.4[72.0]$ & $308.0(365)$ \\
\hline \multicolumn{5}{|c|}{ Up to 6 Months of Follow-Up } \\
\hline
\end{tabular}

Recurrent VTE documented during inpatient stay

\begin{tabular}{|c|c|c|c|c|}
\hline Overall VTE sample $(n=177,885)$ & 3.4 & 8.1 & $41.4[43.4]$ & $156.8(180)$ \\
\hline Matched VTE cohort $(n=16,969)$ & 3.1 & 7.4 & $43.1[44.0]$ & $156.6(180)$ \\
\hline \multicolumn{5}{|l|}{ Stratified by type of index VTE } \\
\hline $\operatorname{DVT}(\mathrm{n}=12,711)$ & 1.9 & 4.5 & $45.1[44.7]$ & $157.8(180)$ \\
\hline $\mathrm{PE}(\mathrm{n}=2,473)$ & 1.5 & 3.7 & 27.2 [30.9] & $150.0(180)$ \\
\hline Both $(\mathrm{n}=1,785)$ & 13.8 & 35.8 & $43.4[44.7]$ & $157.2(180)$ \\
\hline
\end{tabular}

Post-thrombotic syndrome $^{\mathrm{b}}$

\begin{tabular}{l|l|l|l|l}
\hline Overall VTE sample $(\mathrm{n}=153,607)$ & 4.2 & 8.9 & $125.4[26.6]$ & $174.0(180)$ \\
\hline
\end{tabular}

\begin{tabular}{|l|l|l|l|l|l}
\hline Matched VTE cohort $(\mathrm{n}=14,647)$ & 4.2 & 9.0 & $124.7[26.1]$ & $173.8(180)$ \\
\hline
\end{tabular}

Stratified by type of index VTE

\begin{tabular}{|l|l|l|l|l} 
DVT $(\mathrm{n}=11,067)$ & 4.0 & 9.3 & $124.2[26.3]$ & $173.8(180)$ \\
\hline
\end{tabular}

PE $(n=2,033)$

Both $(\mathrm{n}=1,547)$

\begin{tabular}{l|l|l|l|l|}
0.8 & 2.1 & $124.8[27.7]$ & $173.2(180)$ \\
\hline
\end{tabular}

${ }^{a}$ Mean time to event was calculated for patients with an event.

${ }^{b}$ Risk and incidence rate of post-thrombotic syndrome were calculated on the subset of patients with more than 90 days of follow-up.

$D V T=$ deep vein thrombosis; $I R=$ incidence rate; $P E=$ pulmonary embolism; $S D=$ standard deviation; VTE = venous thromboembolism.

3.1\% for female patients. Risk of recurrent VTE increased with number of baseline VTE risk factors: $2.4 \%, 2.7 \%, 3.8 \%$, and $5.6 \%$ for patients with $0,1,2$, and 3 or more baseline VTE risk factors, respectively. The corresponding risks of PTS were 6.2\% for males and $7.8 \%$ for females and $5.6 \%, 6.1 \%, 7.6 \%$, and $9.5 \%$ for patients with $0,1,2$, and 3 or more baseline VTE risk factors, respectively.

\section{Costs Associated with VTE}

VTE patients had significantly higher average PPPY all-cause costs from the payer's perspective compared with no-VTE patients (mean [SD] \$33,531 [\$70,393] vs. \$17,590 [\$42,011]; 
All-Cause and Potentially Disease-Related Health Care Costs Associated with

Venous Thromboembolism in Commercial, Medicare, and Medicaid Beneficiaries

TABLE 3b Risk and Incidence Rates of Exploratory Endpoint Outcomes

for the VTE Cohort Relative to the No-VTE Cohort

\begin{tabular}{|c|c|c|c|c|c|c|c|}
\hline \multirow{3}{*}{$\frac{\text { Exploratory Endpoints }}{\text { Thrombocytopenia }}$} & \multicolumn{2}{|c|}{ VTE Cohort } & \multicolumn{2}{|c|}{ No-VTE Cohort } & \multirow[b]{2}{*}{$\begin{array}{c}\text { Risk Ratio } \\
(95 \% \text { CI) }\end{array}$} & \multirow{2}{*}{$\begin{array}{c}\text { Incidence Rate } \\
\text { Ratio } \\
(95 \% \mathrm{CI}) \\
\end{array}$} & \multirow{3}{*}{$\begin{array}{r}P \text { Value }^{\mathrm{a}} \\
<0.001\end{array}$} \\
\hline & $\begin{array}{c}\text { Risk of } \\
\text { Event (\%) }\end{array}$ & $\begin{array}{c}\text { IR Per } 100 \\
\text { Patient-Years }\end{array}$ & $\begin{array}{c}\text { Risk of } \\
\text { Event (\%) }\end{array}$ & $\begin{array}{c}\text { IR per } 100 \\
\text { Patient-Years }\end{array}$ & & & \\
\hline & 2.8 & 3.8 & 1.2 & 1.7 & $2.3 \quad(2.0-2.7)$ & $2.2 \quad(1.9-2.6)$ & \\
\hline Superficial venous thrombosis & 4.7 & 6.7 & 0.2 & 0.3 & $21.7 \quad(15.6-30.1)$ & $21.5 \quad(15.4-29.9)$ & $<0.001$ \\
\hline Venous ulcer & 1.4 & 2.0 & 0.6 & 0.8 & $2.6 \quad(2.1-3.3)$ & $2.5 \quad(2.0-3.2)$ & $<0.001$ \\
\hline Pulmonary hypertension & 2.6 & 3.5 & 0.9 & 1.3 & $(2.4-3.5)$ & $(2.3-3.3)$ & $<0.001$ \\
\hline Stasis dermatitis & 2.6 & 3.6 & 0.8 & 1.1 & $(2.7-4.0)$ & $(2.7-3.9)$ & $<0.001$ \\
\hline Venous insufficiency & 7.2 & 10.3 & 2.1 & 3.0 & $(3.1-3.9)$ & $(3.0-3.9)$ & $<0.001$ \\
\hline
\end{tabular}

aP values were $<0.001$ for all risk ratios and incidence rate ratios.

$C I=$ confidence interval; $I R=$ incidence rate; VTE = venous thromboembolism.

cost difference $=\$ 15,941,95 \% \mathrm{CI}=\$ 14,819-\$ 17,012$; Figure 2). All-cause hospitalization represented the largest driver of the cost difference between the VTE and the no-VTE groups (mean [SD] $\$ 17,174[\$ 57,397]$ vs. $\$ 6,515[\$ 29,323]$; cost difference $=\$ 10,659,95 \% \mathrm{CI}=\$ 9,846-\$ 11,491)$. Health care costs related to recurrent VTE, PTS, or exploratory endpoints (mean [SD] $\$ 3,141[\$ 17,056]$ vs. $\$ 228$ [\$3,221]; cost difference $=\$ 2,913,95 \% \mathrm{CI}=\$ 2,693-\$ 3,157$ ) represented $18.3 \%$ (i.e., $\$ 2,913$ of $\$ 15,941$ ) of the all-cause cost difference between the VTE group and the no-VTE group (Figure 2).

For the stratified analysis by gender and baseline VTE risk factors, the all-cause mean incremental PPPY costs associated with VTE relative to no-VTE were $\$ 18,678$ for men; $\$ 13,932$ for women; and $\$ 13,275, \$ 14,245, \$ 13,932$, and $\$ 23,206$ for patients with $0,1,2$, and 3 or more baseline VTE risk factors, respectively. The corresponding incremental PPPY costs of recurrent VTE, PTS, or exploratory endpoints were $\$ 3,357$ for men; $\$ 2,583$ for women; and $\$ 2,188, \$ 2,525, \$ 2,360$, and $\$ 4,614$ for patients with $0,1,2$, and 3 or more baseline VTE risk factors, respectively (Table 4).

\section{Discussion}

Based on real-world data, this large retrospective study was conducted to quantify the risk of clinical complications and incremental health care costs associated with VTE using a matched-cohort design. During the period January 2004 through December 2008, a total of 16,969 VTE patients matched with an equal number of no-VTE patients with similar baseline characteristics were studied. VTE was associated with a 3.6\% risk of hospital-documented recurrent VTE and a $7.1 \%$ risk of PTS up to 1 year after the index VTE. VTE was also associated with a significantly higher risk for thrombocytopenia, superficial venous thrombosis, venous ulcer, pulmonary hypertension, stasis dermatitis, and venous insufficiency compared with the no-VTE cohort. Of note, the VTE and no-VTE cohorts were matched exactly on these exploratory endpoints at baseline. Recurrent VTE, PE, and the increased rate of these exploratory endpoints resulted in a $\$ 2,913$ PPPY health care cost burden associated with VTE that was not present during the baseline period (i.e., both cohorts had similar health care costs at baseline).

Several prospective studies have estimated the risk of VTE recurrence following an index thromboembolic event. ${ }^{6,11,38}$ More recently, Prandoni et al. (2007) evaluated 1,626 patients who had discontinued anticoagulation therapy between May 1991 and April 2003 after "a first episode of clinically symptomatic proximal DVT and/or PE." The cumulative incidence of recurrent VTE in this prospective study was $11.0 \%$ after 1 year, $19.6 \%$ after 3 years, and $29.1 \%$ after 5 years. ${ }^{39}$

The comorbidity profile of patients can also affect the magnitude of the estimated risk of VTE recurrence. For example, Christiansen et al. (2005), in a prospective follow-up study of 474 consecutive patients aged 18 to 70 years without malignancy between January 1988 and December 1992, reported that the risk of VTE recurrence was $12.4 \%$ after 5 years. ${ }^{38}$ The authors also found that the odds of thrombotic event recurrence for men were 2.7 times those for women. In the current study, we found that the risk of recurrence was $4.3 \%$ for men and $3.1 \%$ for women.

The estimated risks of VTE recurrence from retrospective studies are generally more conservative than those of prospective cohort studies or randomized trials because of the difficulty associated with the identification of recurrent events. In a retrospective analysis of 8,332 patients hospitalized with a primary discharge diagnosis of DVT or PE identified from the Integrated Health Care Information Services (IHCIS) National Managed Care Database between 1998 and 2004, Spyropoulos and Lin (2007) reported a hospital readmission rate of 5.3\% within 1 year..$^{40} \mathrm{~A}$ population-based cohort study conducted by Heit et al. (2000), using medical records from 1,719 patients with a first lifetime DVT or PE during the 25-year period from 1966 through 1990, reported that the overall probable/ definite cumulative percentage of VTE recurrence was 5.6\% at 1 year. ${ }^{12}$ The risk of VTE recurrence at up to 1 year (mean 
follow-up of 9 months) that we observed in the current study was slightly lower at $3.6 \%$, possibly due to our strict definition of VTE recurrence (hospital documented) and to a different study design and population. Another possible explanation for the lower recurrence rate of VTE is the trend toward outpatient treatment of VTE; the more recent time frame of the current study (2004 to 2008) combined with our definition of hospital-documented VTE recurrence could account for some of the differences we observed when comparing our findings with the literature.

PTS has also been reported to affect up to one-half of DVT patients. ${ }^{6,13,14}$ Since there is no ICD-9-CM diagnosis code for PTS, we used the algorithm developed by MacDougall et al., which defined PTS as the occurrence 90 days or more after the index VTE of a venous imaging procedure and 1 or more of several diagnoses, including varicose veins, postphlebitic syndrome, limb pain and swelling, and other circulatory disorders. ${ }^{16}$ MacDougall et al. reported a PTS risk of 3.8\% in 17,634 patients evaluable between 1997 and 2004. ${ }^{16}$ In the current study using more recent data from 2004 to 2008 and a followup period of up to 1 year, $7.1 \%$ of patients in the VTE cohort experienced PTS.

The cost burden of VTE is significant. Studies based on large U.S. databases reported that the costs of an initial VTE were between $\$ 3,000$ and $\$ 9,500$ per episode of illness, and mean total health care costs associated with VTE over 1 year were estimated to be $\$ 7,590-\$ 33,200$ for DVT, $\$ 13,000-\$ 31,300$ for $\mathrm{PE}$, and up to $\$ 38,300$ for both DVT and PE. ${ }^{16,41}$ Additionally, the mean all-cause cost of hospital-documented recurrent VTE was estimated to be $\$ 12,326$ (DVT: $\$ 11,419$; PE: $\$ 11,014$; DVT + PE: \$19,237). ${ }^{17}$ Spyropoulos and Lin also quantified the annual cost associated with DVT and PE using administrative claims data from February 1998 to June 2004. For a primary diagnosis of DVT and PE, they reported DVT- and PE-related average health care costs during the 12-month follow-up period of $\$ 10,804$ and $\$ 16,644$, respectively. ${ }^{40}$ In the current study using a matched-cohort design with more recent data from January 2004 to December 2008, we found annualized all-cause health care costs of $\$ 33,531$ for the VTE group, compared with $\$ 17,590$ for the no-VTE group, for total incremental all-cause costs associated with VTE of $\$ 15,941$ during the follow-up period of up to 1 year.

Although not directly comparable because of the different study period and population, our estimates concur with previously reported findings that VTE represents a significant cost burden. Moreover, the current study reported real-world potentially disease-related health care costs that represented nearly one-fifth of the incremental all-cause costs associated with VTE. Costs were reported from the payer's perspective. As mentioned by Lancry et al. (2001), there is a need for information on real-world cost assumed by health care payers, who are charged with the responsibility of providing coverage for

\section{TABLE 4 Stratified Results by Gender} and Baseline VTE Risk Factors ${ }^{\mathrm{a}}$

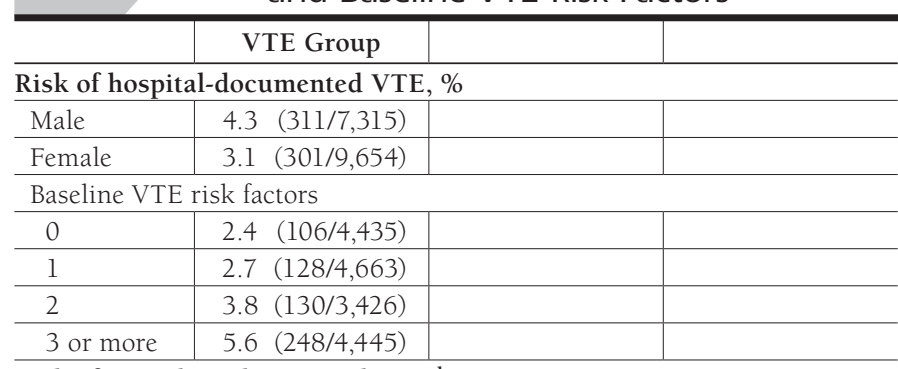

Risk of post-thrombotic syndrome, ${ }^{\mathrm{b}} \%$

\begin{tabular}{l|c|l|l}
\hline Male & $6.2(390 / 6,264)$ & & \\
\hline Female & $7.8(656 / 8,383)$ & & \\
\hline
\end{tabular}

Baseline VTE risk factors

\begin{tabular}{l|c|c|c}
\hline 0 & $5.6(222 / 3,953)$ & & \\
\hline 1 & $6.1(252 / 4,105)$ & & \\
\hline 2 & $7.6(225 / 2,948)$ & & \\
\hline 3 or more & $9.5(347 / 3,641)$ & & \\
\hline & $\begin{array}{c}\text { VTE Group } \\
{[A]}\end{array}$ & $\begin{array}{c}\text { No-VTE Group } \\
{[B]}\end{array}$ & $\begin{array}{c}\text { Cost Difference } \\
\text { [A]-[B] }\end{array}$ \\
\hline
\end{tabular}

\begin{tabular}{l|c|c|c}
\hline \multicolumn{4}{l}{ All-cause costs, mean (\$) } \\
\hline Male & 38,003 & 19,325 & 18,678 \\
\hline Female & 30,208 & 16,276 & 13,932 \\
\hline
\end{tabular}

Baseline VTE risk factors

\begin{tabular}{|c|c|c|c|}
\hline 0 & 18,156 & 4,881 & 13,275 \\
\hline 1 & 24,980 & 10,735 & 14,245 \\
\hline 2 & 34,337 & 20,405 & 13,932 \\
\hline 3 or more & 59,564 & 36,358 & 23,206 \\
\hline \multicolumn{4}{|c|}{ Disease-related costs, mean (\$) } \\
\hline Male & 3,637 & 280 & 3,357 \\
\hline Female & 2,772 & 189 & 2,583 \\
\hline \multicolumn{4}{|c|}{ Baseline VTE risk factors } \\
\hline 0 & 2,197 & 9 & 2,188 \\
\hline 1 & 2,612 & 87 & 2,525 \\
\hline 2 & 2,715 & 355 & 2,360 \\
\hline 3 or more & 5,132 & 518 & 4,614 \\
\hline
\end{tabular}

${ }^{a}$ Evaluated up to 1 year after the index date.

${ }^{b}$ Risk of post-thrombotic syndrome was calculated on the subset of patients with more than 90 days of follow-up.

$S D=$ standard deviation; $V T E=$ venous thromboembolism

high-quality health care services within limited budgets. As the demands are always greater than the budget, tools that can inform decisions on the allocation of limited resources are of interest. ${ }^{42}$

\section{Limitations}

This study is subject to several limitations. The foremost limitation is the inclusion of a nonvalidated measure of potentially disease-related diagnoses in the cost calculations. Second, the objective of the current study was to evaluate the risk and costs of VTE from a managed care perspective. It was beyond the scope of this study to assess whether thromboprophylaxis is beneficial. Therefore, our study was conducted on all VTE 
FIGURE 2 All-Cause and Potentially DiseaseRelated Health Care Costs ${ }^{a}$

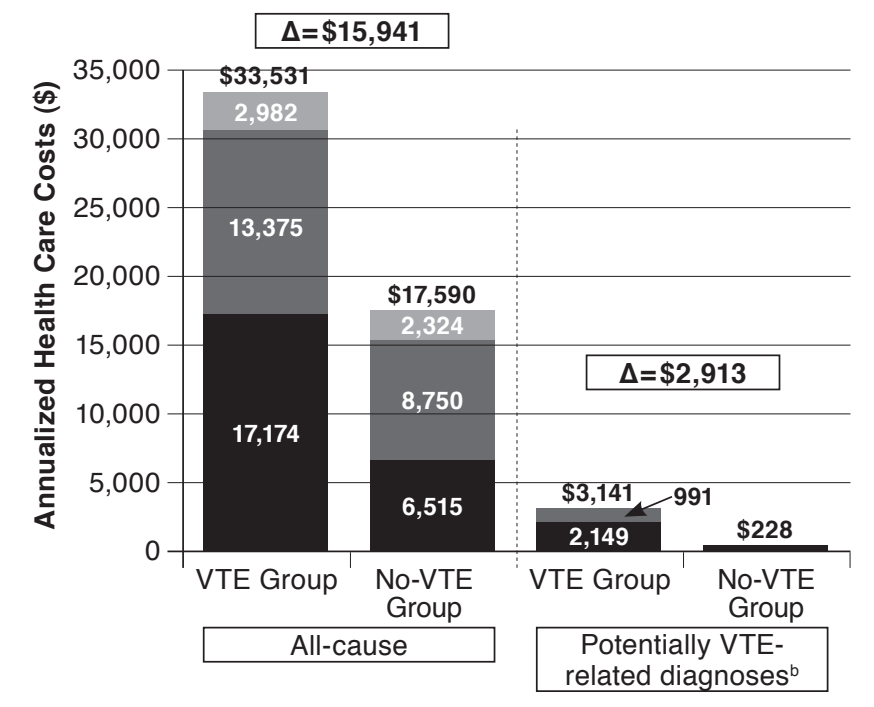

Hospitalization costs Outpatient costs Pharmacy costs

aAll cost differences between the venous thromboembolism (VTE) group and the no-VTE group (i.e., total and categorized by hospitalization, outpatient, and pharmacy costs) were statistically significantly different than 0 at $P<0.001$. The mean cost differences (bootstrapped 95\% confidence intervals) for the all-cause and the potentially VTE-related diagnoses (recurrent VTE, PTS, or exploratory endpoints) were $\$ 15,941(\$ 14,819-\$ 17,012)$ and $\$ 2,913(\$ 2,693-\$ 3,157)$, respectively.

bIncludes VTE, PTS, and exploratory endpoint outcomes (thrombocytopenia, superficial venous thrombosis, venous ulcer, pulmonary hypertension, stasis dermatitis, and venous insufficiency).

PTS = post-thrombotic syndrome; VTE= venous thromboembolism .

patients regardless of thromboprophylaxis and was not specifically focused on a comparison of patients according to thromboprophylaxis use. Further research is warranted to evaluate the potential cost benefit or cost saving associated with VTE prophylaxis in VTE patients. Third, claims databases may contain inaccuracies or omissions in procedures, diagnoses, or costs. Fourth, the study evaluated only direct medical costs. Information to determine the indirect costs of VTE, such as work productivity loss and reduced quality of life, was not available. Fifth, the observational design was susceptible to various biases, such as information or classification bias (e.g., identification of false-positive VTE events). It is also possible that VTE events were undercoded (i.e., false negatives). Sixth, the distribution of the type of insurance in the current study poses limits to the generalizability of the results to the U.S. population. For the U.S. population, the rates of private and government coverage were $67 \%$ and $29 \%$, respectively (not mutually exclusive) in $2008,{ }^{43}$ compared with approximately $2 \%$ government coverage in the present study. Finally, the database did not include mortality data.
Despite these limitations, well-designed observational studies with appropriate statistical techniques adjusting for potential confounding factors through matching techniques can provide valuable information with real-life scenarios and high generalizability.

\section{Conclusions}

In this large matched-cohort study, VTE was associated with a 3.6\% risk of hospital-documented recurrent VTE and a 7.1\% risk of PTS during a follow-up of up to 1 year after an index VTE. VTE was also associated with significant health care cost burden, and potentially disease-related health care costs represented nearly one-fifth of the incremental all-cause costs associated with VTE.

\section{Authors}

PATRICK LEFEBVRE, MA, is Vice President; FRANÇOIS

LALIBERTE, MA, is Senior Economist; and KATHERINE DEA, MA, is Economist, Groupe d'analyse, Ltée, Montréal, Québec, Canada. EDITH A. NUTESCU, PharmD, is Clinical Professor, College of Pharmacy, The University of Illinois at Chicago, Chicago, Illinois. MEI SHENG DUH, MPH, ScD, is Managing Principal, Analysis Group, Inc., Boston, Massachusetts. JOYCE LAMORI, MHS, MBA, is Associate Director, Translational Science; BRAHIM K. BOOKHART, MBA, MPH, is Director, Outcomes Research; WILLIAM H. OLSON, $\mathrm{PhD}$, is Leader, Research and Analysis Strategy; and JEFF SCHEIN, $\operatorname{DrPH}, \mathrm{MPH}$, is Senior Director, Health Economics and Outcomes Research, Janssen Scientific Affairs LLC, Raritan, New Jersey. SCOTT KAATZ, DO, MSc, FACP, is Clinical Associate Professor of Medicine, Henry Ford Hospital, Detroit, Michigan.

AUTHOR CORRESPONDENCE: Patrick Lefebvre, MA, Vice President, Groupe d'analyse, Ltée, 1000 De La Gauchetière Ouest, Bureau 1200, Montréal, QC, Canada H3B 4W5. Tel: 514.394.4471; Fax: 514.394.4461; E-mail: plefebvre@analysisgroup.com.

\section{DISCLOSURES}

Funding to support preparation of this manuscript was provided by Janssen Scientific Affairs, LLC, Raritan, New Jersey. Lefebvre, Laliberté, Duh, and Dea are employees of Analysis Group, Inc., a consulting company that has received research grants from Janssen Scientific Affairs, LLC, and 4 of the authors (Lamori, Bookhart, Olson, and Schein) are employees of Janssen Scientific Affairs, LLC. Nutescu and Kaatz received research grants from Janssen Scientific Affairs, LLC.

Parts of this manuscript were presented at the Academy of Managed Care Pharmacy (AMCP) 23rd Annual Meeting and Showcase, April 27-29, 2011 Minneapolis, Minnesota, and at the 2011 Annual Scientific Symposium of the Hemostasis \& Thrombosis Research Society, April 28-30, 2011, Chicago, Illinois.

All authors contributed to concept and design. The data were collected by Dea, Duh, Laliberté, and Lefebvre and interpreted primarily by Kaatz and Nutescu with the assistance of Lefebvre and Olson. The manuscript was written primarily by Duh, Laliberté, and Lefebvre with the assistance of Dea. Revisions were made primarily by Bookhart, Lamori, and Schein. 


\section{ACKNOWLEDGMENTS}

The authors would like to acknowledge Ruth Sussman, PhD, Chameleon Communications International, New York, New York, who provided limited editorial support with funding from Janssen Scientific Affairs, LLC.

\section{REFERENCES}

1. Heit JA, Cohen AT, Anderson FA Jr, et al. Estimated annual number of incident and recurrent, non-fatal and fatal venous thromboembolism (VTE) events in the U.S. Blood. 2005;106:267a. Poster presented at: 47th Annual Meeting of the American Society of Hematology (ASH); December 10-14, 2005; Atlanta, GA

2. Sandler DA, Martin JF. Autopsy proven pulmonary embolism in hospital patients: are we detecting enough deep vein thrombosis? J R Soc Med. 1989;82(4):203-05

3. Kopcke D, Harryman O, Benbow EW, Hay C, Chalmers N. Mortality from pulmonary embolism is decreasing in hospital patients. J R Soc Med. 2011;104(8):327-31

4. Heit JA. The epidemiology of venous thromboembolism in the community: implications for prevention and management. J Thromb Thrombolysis. 2006;21(1):23-29

5. Kearon C. Natural history of venous thromboembolism. Circulation. 2003;107(23 Suppl 1):I22-30. Available at: http://circ.ahajournals.org/content/107/23_suppl_1/I-22.full.pdf+html. Accessed May 18, 2012.

6. Prandoni P, Lensing AW, Cogo A, et al. The long-term clinical course of acute deep venous thrombosis. Ann Intern Med. 1996;125(1):1-7. Available at: http://www.annals.org/content/125/1/1.full.pdf+html. Accessed May 18, 2012

7. Edelsberg J, Ollendorf D, Oster G. Venous thromboembolism following major orthopedic surgery: review of epidemiology and economics. Am J Health Syst Pharm. 2001;58(Suppl 2):S4-S13.

8. White RH. The epidemiology of venous thromboembolism. Circulation. 2003;107(23 Suppl 1):I4-8. Available at: http://circ.ahajournals.org/content/107/23_suppl_1/I-4.full.pdf+html. Accessed May 18, 2012.

9. Anderson FA Jr, Spencer FA. Risk factors for venous thromboembolism. Circulation. 2003;107(23 Suppl 1):19-16. Available at: http://circ.ahajournals. org/content/107/23_suppl_1/I-9.full.pdf. Accessed May 18, 2012

10. The Columbus Investigators. Low-molecular-weight heparin in the treatment of patients with venous thromboembolism. N Engl J Med. 1997;337(10):657-62. Available at: http://www.nejm.org/doi/pdf/10.1056/ NEJM199709043371001. Accessed May 18, 2012.

11. Hansson PO, Sorbo J, Eriksson H. Recurrent venous thromboembolism after deep vein thrombosis: incidence and risk factors. Arch Intern Med. 2000;160(6):769-74. Available at: http://archinte.ama-assn.org/cgi/ reprint/160/6/769.pdf. Accessed May 18, 2012.

12. Heit JA, Mohr DN, Silverstein MD, Petterson TM, O'Fallon WM, Melton LJ 3rd. Predictors of recurrence after deep vein thrombosis and pulmonary embolism: a population-based cohort study. Arch Intern Med. 2000;160(6):761-68. Available at: http://archinte.ama-assn.org/cgi/ reprint/160/6/761.pdf. Accessed May 18, 2012.

13. Brandjes DP, Büller HR, Heijboer H, et al. Randomised trial of effect of compression stockings in patients with symptomatic proximal-vein thrombosis. Lancet. 1997;349(9054):759-62.

14. Kahn SR, Solymoss S, Lamping DL, Abenhaim L. Long-term outcomes after deep vein thrombosis: postphlebitic syndrome and quality of life. J Gen Intern Med. 2000;15(6):425-29. Available at: http://www.ncbi.nlm.nih.gov/ pmc/articles/PMC1495464/?tool=pubmed. Accessed May 18, 2012.

15. Ginsberg JS, Turkstra F, Buller HR, MacKinnon B, Magier D, Hirsh J. Postthrombotic syndrome after hip or knee arthroplasty: a cross-sectional study. Arch Intern Med. 2000;160(5):669-72. Available at: http://archinte ama-assn.org/cgi/content/full/160/5/669. Accessed May 18, 2012
16. MacDougall DA, Feliu AL, Boccuzzi SJ, Lin J. Economic burden of deepvein thrombosis, pulmonary embolism, and post-thrombotic syndrome. Am J Health Syst Pharm. 2006;63(20 Suppl 6):S5-S15.

17. Bullano MF, Willey V, Hauch O, Wygant G, Spyropoulos AC, Hoffman L. Longitudinal evaluation of health plan cost per venous thromboembolism or bleed event in patients with a prior venous thromboembolism event during hospitalization. J Manag Care Pharm. 2005;11(8):663-73. Available at: http:// www.amcp.org/data/jmcp/Original\%20Research\%20663-673.pdf.

18. Ollendorf DA, Vera-Llonch M, Oster G. Cost of venous thromboembolism following major orthopedic surgery in hospitalized patients. Am J Health Syst Pharm. 2002;59(18):1750-54

19. Oster G, Ollendorf DA, Vera-Llonch M, Hagiwara M, Berger A, Edelsberg $\mathrm{J}$. Economic consequences of venous thromboembolism following major orthopedic surgery. Ann Pharmacother. 2004;38(3):377-82.

20. O'Brian JA, Caro JJ. Direct medical cost of managing deep vein thrombosis according to the occurrence of complications. Pharmacoeconomics. 2002;20(9):603-15.

21. Bagelman SM, Hursting MJ, Aghababian RV, McCollum D. Heparininduced thrombocytopenia from venous thromboembolism treatment. Intern Med. 2005;258(6):563-72.

22. Kitchens CS. Thrombocytopenia due to acute venous thromboembolism and its role in expanding the differential diagnosis of heparin-induced thrombocytopenia. Am J Hematol. 2004;76(1):69-73.

23. Coon WW, Willis PW 3rd, Keller JB. Venous thromboembolism and other venous disease in the Tecumseh Community Health Study. Circulation. 1973;48(4):839-46. Available at: http://circ.ahajournals.org/content/48/4/839.long. Accessed May 18, 2012

24. Decousus H, Quéré I, Presles E, et al. Superficial venous thrombosis and venous thromboembolism: a large, prospective epidemiologic study. Ann Intern Med. 2010;152(4):218-24.

25. Heit JA. The epidemiology of venous thromboembolism in the community. Arterioscler Thromb Vasc Biol. 2008;28(3):370-72. Available at: http:// www.ncbi.nlm.nih.gov/pmc/articles/PMC2873781/?tool=pubmed. Accessed May 18, 2012

26. White JV, Ryjewski C. Chronic venous insufficiency. Perspect Vasc Surg Endovasc Ther. 2005;17(4):319-27.

27. Pengo V, Lensing AW, Prins MH, et al. Incidence of chronic thromboembolic pulmonary hypertension after pulmonary embolism. N Engl J Med. 2004:350(22):2257-64. Available at: http://www.nejm.org/doi/full/10.1056/ NEJMoa032274. Accessed May 18, 2012.

28. Vedantham S. Deep venous thrombosis: the opportunity at hand. Am J Roentgenol. 2009;193(4):922-27.

29. Wolinsky CD, Waldrof H. Chronic venous disease. Med Clin North Am. 2009;93(6):1333-46.

30. Yamaki T, Nozaki M. Patterns of venous insufficiency after an acute deep vein thrombosis. J Am Coll Surg. 2005;201(2):231-38.

31. Juhan CM, Alimi YS, Barthelemy PJ, Fabre DF, Riviere CS. Late results of iliofemoral venous thrombectomy. J Vasc Surg. 1997;25(3):417-22.

32. Rosenbaum PR, Rubin DB. Constructing a control group using multivariate matched sampling methods that incorporate the propensity score. The American Statistician. 1985;39(1):33-38.

33. Hosmer DW, Lemeshow S. Applied Logistic Regression. 2nd ed. New York, NY: John Wiley \& Sons; 2000

34. Diehr P, Yanez D, Ash A, Hornbrook M, Lin DY. Methods for analyzing health care utilization and costs. Annu Rev Public Health. 1999;20:125-44.

35. McAdam-Marx C, McGarry LJ, Hane CA, Biskupiak J, Deniz B, Brixner DI. All-cause and incremental per patient per year cost associated with chronic hepatitis $C$ virus and associated liver complications in the United States: a managed care perspective. J Manag Care Pharm. 2011;17(7):53146. Available at: http://www.amcp.org/WorkArea/DownloadAsset. aspx?id=10710. 


\section{All-Cause and Potentially Disease-Related Health Care Costs Associated with Venous Thromboembolism in Commercial, Medicare, and Medicaid Beneficiaries}

36. Efron B, Tibshirani RJ. An Introduction to the Bootstrap. New York, NY: Chapman and Hall;1994.

37. Mooney CZ, Duval RD. Bootstrapping: A Nonparametric Approach to Statistical Inference. Newbury Park, CA: Sage Publications; 1993.

38. Christiansen SC, Cannegieter SC, Koster T, Vandenbroucke JP, Rosendaal FR. Thrombophilia, clinical factors, and recurrent venous thrombotic events. JAMA. 2005;293(19):2352-61. Available at: http://jama.amaassn.org/content/293/19/2352.full.pdf+html. Accessed May 18, 2012.

39. Prandoni P, Noventa F, Ghirarduzzi A, et al. The risk of recurrent venous thromboembolism after discontinuing anticoagulation in patients with acute proximal deep vein thrombosis or pulmonary embolism. A prospective cohort study in 1,626 patients. Haematologica. 2007;92(2):199-205. Available at: http:// www.haematologica.org/content/92/2/199.full.pdf. Accessed May 18, 2012.
40. Spyropoulos AC, Lin J. Direct medical costs of venous thromboembolism and subsequent hospital readmission rates: an administrative claims analysis from 30 managed care organizations. J Manag Care Pharm. 2007;13(6):475-86. Available at: http://www.amcp.org/data/jmcp/pages\%20 475-86.pdf.

41. Ruppert A, Steinle T, Lees M. Economic burden of venous thromboembolism: a systematic review. J Med Econ. 2011;14(1):65-74.

42. Lancry PJ, O'Connor R, Stempel D, Raz M. Using health outcomes data to inform decision-making: healthcare payer perspective. Pharmacoeconomics. 2001;19(Suppl 2):S39-S47.

43. DeNavas-Walt C, Proctor B, Smith J. Income, poverty, and health insurance coverage in the United States: 2009. U.S. Census Bureau. September 2010. Available at: http://www.census.gov/prod/2010pubs/p60-238.pdf. Accessed May 18, 2012.

\section{APPENDIX Diagnosis Codes Used to Identify Post-Thrombotic Syndrome and Exploratory Endpoints}

\begin{tabular}{|c|c|c|}
\hline Medical Term & ICD-9-CM code(s) & Description \\
\hline \multicolumn{3}{|l|}{ Post-thrombotic syndrome ${ }^{a}$} \\
\hline Pain & 729.5 & Pain in limb \\
\hline Swelling of the limb & 729.81 & Swelling of limb \\
\hline Varicose veins of the lower extremities & $454 . x$ & Varicose veins of lower extremities \\
\hline Postphlebitic syndrome & 459.1 & Postphlebetic syndrome \\
\hline Other disorders of the circulatory system & $459.8 x$ & Other specified disorders of circulatory system \\
\hline \multicolumn{3}{|l|}{ Exploratory endpoints ${ }^{b}$} \\
\hline \multirow{3}{*}{ Thrombocytopenia } & 287.3 & Primary thrombocytopenia \\
\hline & 287.4 & Secondary thrombocytopenia \\
\hline & 287.5 & Thrombocytopenia unspecified \\
\hline Superficial venous thrombosis & 451.0 & Phlebitis and thrombophlebitis of superficial vessels of lower extremities \\
\hline \multirow{6}{*}{ Venous ulcer } & 454.0 & Varicose veins of lower extremities with ulcer \\
\hline & 454.2 & Varicose veins of lower extremities with ulcer and inflammation \\
\hline & 459.11 & Postphlebitic syndrome with ulcer \\
\hline & 459.13 & Postphlebitic syndrome with ulcer and inflammation \\
\hline & 459.31 & Chronic venous hypertension with ulcer \\
\hline & 459.33 & Chronic venous hypertension with ulcer and inflammation \\
\hline \multirow{3}{*}{ Pulmonary hypertension } & 415.0 & Acute cor pulmonale \\
\hline & 416.0 & Primary pulmonary hypertension \\
\hline & 416.8 & Other chronic pulmonary heart diseases \\
\hline Stasis dermatitis & 454.1 & Varicose veins of lower extremities with inflammation \\
\hline Venous insufficiency & 459.81 & Venous (peripheral) insufficiency, unspecified \\
\hline
\end{tabular}

